\title{
Aesthetic Education of Vocal Music Teaching in Music Education
}

\author{
Hao Zhang \\ Department of Music and Performing, Sichuan University of Arts and Science, \\ Dazhou 635000, Chinia
}

Keywords: Music education; Vocal music teaching; Aesthetic education

\begin{abstract}
The continuous reform of our country's teaching system puts higher requirements on music education. Teachers must not only impart basic music knowledge to students and improve their musical quality, but also permeate aesthetic education in the classroom to promote students' all-round development. In music education, vocal music teaching courses occupy an important position. Teachers can teach aesthetic knowledge in vocal music teaching and create a good learning environment for students. This paper will specifically discuss the connotation, importance and main strategies of aesthetic education in professional vocal music teaching in music education, hoping to provide some references for related people.
\end{abstract}

\section{Introduction}

Compared with other majors, music education is unique and has strong humanistic characteristics. Professional teachers also undertake the important task of humanistic education while conducting music education. Vocal music teaching is the main subject of music education course. In order to realize the goal of educating people, it is necessary to penetrate aesthetic education in vocal music teaching. Many teachers neglect the importance of aesthetic education, which makes students unable to fully appreciate the aesthetics of the music or reach a spiritual agreement with composers. In teaching process, teachers should give full play to the role of aesthetic education, allow students to enter the music world created by composers and feel the joy and beauty that music brings.

\section{Inadequacies of Vocal Music Teaching In Music Education}

Lack of aesthetic education. Aesthetic education is an important part of music education. Only aesthetic education for students can reflect the humanistic nature of music education and can successfully accomplish the task of talent cultivation of music education. Looking at the current teaching situation of music education in our country, we can find that many teachers do not realize the value of aesthetic education and they break the connection between aesthetic education and music education.Due to the lack of aesthetic education, students cannot feel the thoughts or feelings of composers in music and cannot grasp the themes of the music[1].

Poor teaching effectiveness. Students at particular stages of growth are prone to inattention. In order to allow students to invest themselves in the classroom, teachers need to enhance the interest of classroom and attract students' attention. The application of modern educational technology in classrooms does not only enrich teaching content, but also improves teaching efficiency. Many teachers ignore the importance of modern educational technology in teaching process and still use traditional teaching programs, resulting in boring teaching content.

Insufficient student interests. In the context of the reform of teaching system, students became the main body of the classroom. As guides for students, teachers need to respect students' main status and meet their learning needs. It must be noted that many teachers in music education are still constrained in exam-oriented education and take themselves as the center. These teachers instill students with theories in class, which enables students to passively accept music knowledge, which greatly suppress students' interests in learning. 


\section{Connotation and Effect of Aesthetic Education of Vocal Music Teaching in Music Education}

Connotation. Music is a cultural category. To learn music culture, we must explore the aesthetic value of music culture. There are many beautiful things in real life. The process of discovering beauty in real life is the process of elevating the aesthetic ability of people.For individuals, aesthetic education is very important. In the process of aesthetic experience, students will recognize the beauty in real life, experience the beauty of natural scenery and the truth, the goodness and the beauty of human nature, and enhance their own moral level and cognitive level in a subtle manner.For a long time, China has implemented exam-oriented education, which has great disadvantages. Under the rigid teaching system, teachers did not aesthetically educate students, which hindered students' healthy development. With the continuous reform of teaching system and the continuous development of quality education, the vocal music teaching in music education is facing some new changes[2]. The importance of aesthetic education is becoming more and more prominent. In order to achieve the goal of cultivating talents, teachers have constructed a new vocal music teaching system. Aesthetic education is an important part of vocal music teaching system. In the teaching process, teachers pay attention to the explanation of theoretical knowledge and the cultivation of aesthetic consciousness, which lays a solid foundation for the overall development of students.

Effect. Infiltrating aesthetic education in vocal music teaching can realize the creation of artistic beauty. Music works have the characteristics of beauty and music culture has aesthetic characteristics. To analyze a piece of music work, the unique beauty must be understood, making students feel the unique charms of the music work. When carrying out vocal music teaching, teachers of music education must not only introduce basic music knowledge to students, improve students' professional music literacy, but also cultivate students' creative thinking and guide students in artistic creation. Students are lack of experience in the field of art creation. Aesthetic education can enrich students' emotional awareness and allow them to discover beauty and feel beauty.

Infiltrating aesthetic education in vocal music teaching can beautify students' minds. The focus of aesthetic education is to beautify students' minds and realize students' moral growth. Therefore, in the process of aesthetic education, teachers need to help students form the correct values and allow them to have a certain aesthetic ability. There are many initiatives in aesthetic education. Teachers can allow students to analyze the lyrics of musical works, and also allow students to appreciate the beauty of musical tunes. In emotional interaction, the friendly relationship between students and teachers is established. Students can participate more actively in music education and learn aesthetic culture.

Infiltrating aesthetic education in vocal music teaching can make up for the insufficiency of the traditional teaching system. As mentioned above, there are still some problems in the current vocal music teaching of China's music education. Many teachers do not carry out aesthetic education in classroom, resulting in students' lack of music appreciation ability and hindering students' healthy growth. The music education covers a wide range of topics, including basic musical knowledge and musical skills as well as the beauty of music and art. Aesthetic education can enable students to linger in the ocean of music, realize the beauty of music arts, exert the effectiveness of music education and improve the efficiency of vocal music teaching[3].

\section{Effective Strategies of Aesthetic Education in Vocal Music Teaching in Music Education}

Optimize teaching content. Teachers are the guides for students and occupy a very important position in students' learning process. In the classroom of vocal music teaching, teachers, students and teaching materials are indispensable. Only by balancing these three elements can we improve the efficiency of vocal music teaching and optimize the quality of vocal music teaching. In order to enable students to have aesthetic skills, teachers should carefully select teaching contents so that vocal music teaching can meet students' cognitive level. In vocal music teaching, teachers must not only guide students in breathing exercises, vocal exercises, etc., but also guide students in music 
tunes to experience the beauty of music. In vocal music teaching, teachers often have to carry out vocal range exercises. In order to help students form a broad vocal range, teachers should adopt a step-by-step approach that allows students to have a deeper understanding of their own vocal range. There are many music works that can be selected in vocal music teaching. Different works have different characteristics and different educational significance for students. World famous music works with higher aesthetic values should be chosen for students to appreciate. In a period of growth, students are easily distracted. Therefore, teachers should use a variety of teaching methods to set a level of learning goals for students.

Theory combines with practice. In vocal music teaching classroom, music theory and music practice are indispensable. Aesthetic education should not only be combined with music theory, but also combined with music practice. Music education aims at cultivating music teachers needed by society. In order to successfully achieve the goal of talent cultivation, teachers of music education need to improve the overall quality of students and emphasize music education and aesthetic education. In the process of vocal music teaching, teachers must first teach students basic music knowledge, such as music theory, music vocal skills, breathing practice methods and so on. While explaining theoretical knowledge to students, teachers should fully examine students' individualized learning needs and carry out teaching according to their psychological characteristics. Different students' growth experiences and learning characteristics also show greater differences. Teachers should focus on teaching and let students enhance their aesthetic awareness in music practice. Before introducing courses, teachers can solicit the opinions of students, select suitable music works, allow students to appreciate music aesthetically, mobilize the subjective initiative of students and combine music education with aesthetic education[4].

Conduct demonstration exercises. Teachers are guides for students, and they are tasked with dispelling students' preaching. When students practice vocal music, they will encounter a series of problems. Teachers need to solve students' learning problems and improve students' vocal level. Teacher demonstration plays a crucial role in the individual development of students. The better the teacher demonstration is, the more interests of students in learning will be. The worse the teacher demonstration is, the less interests of students in learning will be. Glamorous singing can quickly attract students' attention and allow students to immerse themselves in the wonderful singing of teachers. Therefore, teachers need to improve the quality of demonstration and add the charm of demonstration. Students are at a special stage of growth. They have strong cognitive ability for figurative things but weak cognitive ability for abstract things. The aesthetic education has abstract features. Many students have weak grasp of aesthetic education, which affects the efficiency of aesthetic education quality. When performing demonstration, teachers should first select a familiar song to let students listen to and analyze the musical tune. After demonstration, teachers need to allow students to imitate to sing the song and introduce the creative background, so as to gradually develop students' ability to experience.

Guide aesthetic evaluation. After the completion of vocal music teaching, teachers should evaluate students aesthetically. The aesthetic evaluation mainly includes the following components: The first is to evaluate students' aesthetic consciousness, and the second is to evaluate students' aesthetic qualities. In order to form a scientific evaluation system, teachers should guide students to make aesthetic judgments so that students can accurately determine which things are beautiful and which are ugly. Teachers play and allow students to appraise music clips. According to students' appreciation results, teachers can encourage or guide students so that students can master the effective music appreciation methods.

Understand music equipment. In order to carry out vocal music teaching courses, music equipment is essential. Music equipment is the basis for the formation of music. Under the influence of music equipment, music activities are more complete and music works are more fluent. The process of vocal music teaching is actually the process of music equipment playing the role. In order to allow students to correctly understand and reasonably apply music equipment, teachers should introduce the knowledge of different music equipment, such as the source of the equipment, the use of equipment and so on. In guiding students to understand music equipment, teachers should 
also play audio of different equipment and let students feel the artistic beauty of music equipment, in order to achieve the goal of aesthetic education[5].

\section{Conclusion}

To sum up, the continuous reform of China's teaching system puts higher requirements on music education. With the ultimate goal of cultivating talents needed by society, the music education must promote the overall development of students. Music is a humanistic subject. Teachers need to penetrate aesthetic education in music teaching class, and integrate music education with aesthetic education. Vocal music teaching is an important part of music education courses. Teachers can take vocal music teaching classroom as a carrier to develop music aesthetic education.

\section{References}

[1] Andrea Jacobs, Joyce Goodman. Music in the 'Common' Life of the School: Towards an Aesthetic Education for All in English Girls' Secondary Schools in the Interwar Period. History of Education, 2006, 35(6).

[2] Bing XU, Jing SUN. Studies to Chinese College Music Education Management Reform and Development of Countermeasures. Studies in Sociology of Science, 2011, 2(2).

[3] Xia DAN. Discussion on Reflection of Educational Value in Public Music Education of Normal Colleges. Higher Education of Social Science, 2015, 8(3).

[4] José Luis Aróstegui, Robert Stake, Helen Simons. Music education for the 21st century: Epistemology and ontology as bases for student aesthetic education. Education Policy Analysis Archives, 2004, 12.

[5] Kingston Chukwunonyelum Ani Casimir, Orajaka Sussan Nwakego, Emmanuel Umezinwa. The Need for a Paradigm Shift in Philosophy, Music and African Studies: A Trilogical Identification of Three Conceptual Relevancies in State Tertiary Education. Open Journal of Political Science, 2015, 05(02). 